\title{
Vocabulary Learning Strategies of Turkish EFL Learners: A Focus on Gender*
}

\section{Hatice Okyar}

hokyar@erbakan.edu.tr

Necmettin Erbakan University, Konya, Turkey

\begin{abstract}
This study aimed to (a) identify vocabulary learning strategies (VLSs) employed by Turkish EFL learners; (b) determine whether the use of VLSs varies by gender. To achieve these aims, the vocabulary learning strategies scale developed by Kocaman and Kizilkaya Cumaoglu (2014) was administered to preparatory school students $(n=209)$ at a state university in Turkey. Descriptive statistics (means, standard deviation) and an independent-samples t-test were used for statistical analyses. The results revealed that the frequency of VLS use was at a medium level. In addition, analysis of the sub-dimensions of the scale showed that memory, cognitive, compensation and social strategies were used at a medium frequency level, while metacognitive and affective strategies were used at a high frequency. When VLS use was analyzed with respect to gender, a significant difference was seen between males and females, with female students having a higher total mean score than male students. Also, female students reported more use of memory, cognitive, compensation, metacognitive and affective strategies; however, no statistically significant gender difference was found regarding the frequency of the use of social strategies.
\end{abstract}

Keywords: vocabulary, vocabulary learning strategies, EFL, gender, female and male L2 learners

How to cite:

Okyar, H. (2021). Vocabulary Learning Strategies of Turkish EFL Learners: A Focus on Gender. Journal of English Teaching, 7(1), 43-54. DOI: https://doi.org/10.33541/jet.v7i1.2289

\footnotetext{
* An earlier version of this paper was presented at the $2^{\text {nd }}$ ILTERG (International Language Teacher Education Research Group) Conference, 16-17 October, 2020, online
} 


\section{INTRODUCTION}

The importance of vocabulary knowledge in language learning has been underlined by many different researchers so far. This is because vocabulary knowledge forms the basis of the four main language skills, namely, listening, speaking, reading and writing (Brown, 2007). Besides, numerous studies report a positive relationship between learners' vocabulary knowledge and language performance (Schmitt, 2010). Considering this fact, it is necessary for learners to enrich their vocabulary size to be successful in language. Moreover, learners need to gain great competence in various aspects of word knowledge, which, as Nation (2000, p.40) states, consists of three main areas: knowledge of form (e.g. spoken form, written form), knowledge of meaning (e.g. concepts and referents), and knowledge of use (e.g. grammatical functions of a word). Nation explains these three key components in detail from the perspective of receptive $(\mathrm{R})$ and productive $(\mathrm{P})$ knowledge as follows:

Table 1. "What is involved in knowing a word", (Nation, 2000, pp. 40-41)

\begin{tabular}{|c|c|c|c|}
\hline \multirow[t]{6}{*}{ Form } & \multirow{2}{*}{ spoken } & $\mathrm{R}$ & What does the word sound like? \\
\hline & & $\mathrm{P}$ & How is the word pronounced? \\
\hline & \multirow[t]{2}{*}{ written } & $\mathrm{R}$ & What does the word look like? \\
\hline & & $\mathrm{P}$ & How is the word written and spelled? \\
\hline & \multirow[t]{2}{*}{ word parts } & $\mathrm{R}$ & What parts are recognizable in this word? \\
\hline & & $\mathrm{P}$ & What word parts are needed to express the meaning? \\
\hline \multirow[t]{6}{*}{ Meaning } & \multirow[t]{2}{*}{ form and meaning } & $\mathrm{R}$ & What meaning does this word form signal? \\
\hline & & $\mathrm{P}$ & What word form can be used to express this meaning? \\
\hline & \multirow{2}{*}{ concept and referents } & $\mathrm{R}$ & What is included in the concept? \\
\hline & & $\mathrm{P}$ & What items can the concept refer to? \\
\hline & \multirow[t]{2}{*}{ associations } & $\mathrm{R}$ & What other words does this make us think of? \\
\hline & & $\mathrm{P}$ & What other words could we use instead of this one? \\
\hline \multirow[t]{6}{*}{ Use } & \multirow[t]{2}{*}{ grammatical functions } & $\mathrm{R}$ & In what patterns does the word occur? \\
\hline & & $\mathrm{P}$ & In what patterns must we use this word? \\
\hline & \multirow[t]{2}{*}{ collocations } & $\mathrm{R}$ & What words or types of words occur with this one? \\
\hline & & $\mathrm{P}$ & What words or types of words must we use with this one? \\
\hline & \multirow[t]{2}{*}{$\begin{array}{l}\text { constraints on use } \\
\text { (register, frequency...) }\end{array}$} & $\mathrm{R}$ & $\begin{array}{l}\text { Where, when, and how often would we expect to meet this } \\
\text { word? }\end{array}$ \\
\hline & & $\mathrm{P}$ & Where, when, and how often can we use this word? \\
\hline
\end{tabular}

As is clear from this table, word knowledge, together with form and meaning, requires comprehensive knowledge about when, how, where to use words. However, Zimmerman (2014) points to the problem that students learn only a limited number of words during language classes, and they do not often gain full knowledge regarding the words they learn, and therefore they need to be trained to improve their own vocabulary repertoire. Based on this explanation, we can emphasize the importance of VLS awareness as using strategies effectively can expand learners' vocabulary knowledge (Schmitt, 2000; Zimmerman, 2014). For this reason, it is important for teachers to identify to what extent their students are aware of VLSs and to what extent they use these strategies while learning vocabulary. Additionally, it is crucial to know whether both male 
and female students equally benefit from VLSs. Considering this, the present study tries to determine whether the EFL students in this study's sample uses VLSs, and whether there is a difference between male and female students in terms of VLS use.

\section{Vocabulary Learning Strategies}

Researchers have defined VLSs in connection with language learning strategies in general. To begin with, Zimmerman (2014, p.297) defines VLSs as "planned approaches" and they are employed to find out what a word means through some methods like the use of dictionaries, analysis of parts of speech, getting help from context to guess the meaning, and so on. Zimmerman adds that VLSs are also employed to comprehend how a word is used through negotiation with peers, vocabulary notebooks, L2 movies, songs and so on. Another definition comes from Jimenez Catalan (2003) who underlines that VLSs refer to the:

"knowledge about the mechanisms (processes, strategies) used in order to learn vocabulary as well as steps or actions taken by students (a) to find out the meaning of unknown words, (b) to retain them in long-term memory, (c) to recall them at will, and (d) to use them in oral or written mode" (p. 56).

Schmitt (2000) defines good learners as the ones who consciously organize their vocabulary learning process and employ different types of strategies simultaneously to learn and remember target words. According to Schmitt (2000), the frequently used VLSs are "memorization, repetition, and taking notes on vocabulary" which seem easier to apply when compared to the more complicated strategies like "imagery, inferencing, Keyword Method" (p. 132). Different researchers classified VLSs in different ways. For instance, Nation (2000, pp. 353-354) divides VLSs into three categories as "planning, sources, and processes" as seen below:

Table 2. "A taxonomy of kinds of vocabulary learning strategies", (Nation, 2000, pp. 353-354)

\begin{tabular}{ll}
\hline General class of strategies & Types of strategies \\
\hline Planning: Choosing what to focus on and & Choosing words \\
when to focus on it & Choosing the aspects of word knowledge \\
& Choosing strategies \\
& Planning repetition \\
\hline Sources: Finding information about words & Analysing the word \\
& Using context \\
& Consulting a reference source in L1 or L2 \\
& Using parallels in L1 and L2 \\
\hline Processes: Establishing knowledge & Noticing \\
& Retrieving \\
& Generating \\
\hline
\end{tabular}

Furthermore, Schmitt (1997), based on the general learning strategies of Oxford (1990), categorizes VLSs as follows: determination strategies, social strategies, memory strategies, cognitive strategies, and metacognitive strategies. Schmitt (2000, pp.135-136) explains each category as in the following: 
Determination strategies: These strategies refer to "discovering a new word's meaning without recourse to another person's expertise" (e.g. guessing meaning from context, inferring meaning through L1-L2 cognates) (p. 135).

Social strategies: They are defined as interacting with others to learn and develop vocabulary knowledge (e.g. getting help from peers or teachers to get information about a new word).

Memory strategies: They are also known as mnemonics and refer to making associations with the word and some knowledge gained before through imagery and so on.

Cognitive strategies: As Schmitt puts forward, cognitive strategies are "similar to memory strategies, but are not focused so specifically on manipulative mental processing; they include repetition and using mechanical means to study vocabulary, including the keeping of vocabulary notebooks" (p. 136).

Metacognitive strategies: These strategies refer to planning vocabulary learning process and trying to find out the best methods to study and improve vocabulary.

Previous research regarding VLSs has provided important insights into language learners' VLS use. Different types of VLSs were reported to be used in different contexts. For example, in Lee's (2007) study with 466 Korean university learners learning English as a foreign language, it was stated that students' reported use of VLSs were, respectively, as follows: cognitive strategies, memory strategies, metacognitive strategies, and social strategies. While the most frequently used strategy was cognitive strategies, the least frequently used strategy was social strategies. In her study with 398 eighth-grade EFL learners in Turkey, Mirioglu (2020) found that cognitive strategies were the most frequently employed VLSs followed by determination strategies, metacognitive strategies, memory strategies, and social strategies, respectively. Another study conducted by Tilfarlioglu and Bozgeyik (2012) investigated VLS use of 252 universitylevel English preparatory school students at a state university in Turkey. The study found that out of six VLS categories (i.e. determination, metacognitive, memory, cognitive, social/discovery social/consolidation), determination strategies were the most frequently employed strategies. Contrary to this, social/consolidation strategies were found to be the least favored strategies. These studies show that VLS use can vary based on learners' age, L2 proficiency level, different learning contexts, and other variables like gender. The present study focused only on the gender factor as mentioned below.

\section{Vocabulary Learning Strategies and Gender}

According to Jimenez Catalan (2003), gender has not been the focus of L2 learning and teaching research. Besides that, much uncertainty still exists about the relation between the use of VLSs and gender. Researchers like Oxford, Nyikos, and Ehrman (1988) put a great emphasis on the integration of gender as a variable in research studies related to language learning strategies because it is "a classic and significant predictor in other educational, psychological, and linguistic research" (p. 321). Additionally, Gu (2002) underlines that gender is an important variable in determining VLSs. However, there are very few studies with a focus on gender and VLS use in second and foreign language learning literature and the existing studies show disparities. For instance, Jimenez Catalan (2003) carried out a descriptive study with 581 (279 males, 302 females) students who speak Spanish and learn English $(\mathrm{N}=450)$ and Basque $(\mathrm{N}=131)$ as a second language to find the gender difference in VLS use. The findings revealed that there was a significant difference between male and female students regarding the number of vocabulary Okyar: Vocabulary Learning Strategies of Turkish EFL Learners: A Focus on Gender DOI: https://doi.org/10.33541/jet.v7i1.2289 
strategies used. That is to say, female students outperformed their male counterparts in terms of overall strategy usage percentage. Likewise, Gu (2002) investigated adult Chinese EFL students' vocabulary strategy use and found that female students reported using more VLSs (nearly all of them) when compared to their male counterparts. Contrary to these findings, Lee (2007) conducted a study with 466 university-level Korean EFL learners (206 males and 260 females) and reported that there was no significant gender difference with regard to type and frequency of VLS use. In a similar vein, Wei (2007) carried out a study with 60 (23 males and 37 females) university-level (sophomores) Chinese students. In that study, students reported using VLSs at a medium level, and there was no significant difference between males and females in terms of VLS use. These different results make it difficult to draw general conclusions about gender difference in terms of VLS use and require more research to be conducted. Considering these shortcomings in the literature, this study focuses on the following research questions:

1. What kind of VLSs do Turkish EFL students report to use?

2. Do male and female students differ in terms of VLS use?

\section{METHODOLOGY}

\section{Participants}

209 Turkish EFL students at a state university participated in this study, 108 males and 101 females. The students were taking B1-level (pre-intermediate level) English classes at preparatory school when the data were collected, and the total amount of English instruction was 30 hours per week. The average age for the total sample was 19.3 years. The table below presents the gender distribution of the participants in the study:

Table 3. Distribution of subjects by gender

\begin{tabular}{lcc}
\hline Gender & $\mathbf{N}$ & $\mathbf{\%}$ \\
\hline Male & 108 & 51.7 \\
Female & 101 & 48.3 \\
Total & 209 & 100 \\
\hline
\end{tabular}

\section{Data Collection Instrument}

This study employed vocabulary learning strategies in foreign languages scale by Kocaman and Kizilkaya Cumaoglu (2014) as a data collection tool. These researchers developed the scale considering Oxford's (1990) "The Strategy Inventory for Language Learning (SILL)." It was composed of thirty-two questions in total and six subdimensions as follows: memory strategies, cognitive strategies, compensation strategies, metacognitive strategies, affective strategies, and social strategies. The thirty-two items were rated on a 5-point likert scale ranging from $1=$ never to 5= always, and the scores, as suggested by the developers of the scale, were interpreted as follows: low (1-2.4), medium (2.5-3.4), high (3.5-5). In this study, the Cronbach's alpha for the scale was found as .851, which corresponds to high reliability.

\section{Data Analysis}

In the present study, quantitative analysis was carried out on the data collected from the questionnaire. Descriptive statistics were performed in order to determine the type and frequency of VLSs reported to be used by the students. In addition to this, an independent 
samples t-test was conducted to find out whether there was a gender-related difference in terms of VLS use.

\section{FINDINGS}

\section{Vocabulary Learning Strategies of Turkish EFL Students}

The table below shows the mean scores of the entire VLS scale and its sub-dimensions. As seen from the table, students reported using VLSs at a medium level $(\mathrm{M}=3.12, \mathrm{SD}=$ $.52)$. The most frequently used VLS was affective strategies $(\mathrm{M}=3.59, \mathrm{SD}=.67)$ followed by metacognitive strategies $(\mathrm{M}=3.55, \mathrm{SD}=.77)$. The mean scores of other strategies were, respectively, as follows: memory strategies $(\mathrm{M}=3.04, \mathrm{SD}=.67)$, compensation strategies $(\mathrm{M}=2.98, \mathrm{SD}=.83)$, cognitive strategies $(\mathrm{M}=2.97, \mathrm{SD}=.77)$, social strategies $(\mathrm{M}=2.69$, $\mathrm{SD}=.87)$. As is clear, the least frequently used strategy among the other VLS subcategories was social strategies.

Table 4. Participants' VLS use results based on the total VLS scale and sub-dimensions

\begin{tabular}{lccc}
\hline VLS sub-dimensions & $\mathbf{N}$ & $\overline{\boldsymbol{x}}$ & SD \\
\hline Memory strategies & 209 & 3.04 & .67 \\
Cognitive strategies & 209 & 2.97 & .77 \\
Compensation strategies & 209 & 2.98 & .83 \\
Metacognitive strategies & 209 & 3.55 & .77 \\
Affective strategies & 209 & 3.59 & .67 \\
Social strategies & 209 & 2.69 & .87 \\
Total VLS scale & 209 & 3.12 & .52 \\
\hline
\end{tabular}

*(1.0 - 2.4: low; 2.5-3.4: medium, and 3.5-5.0: high)

Subcategories of VLSs were further analyzed in detail. The following table shows the distribution of memory strategies. In this category, according to the students' reports, the most frequently used memory strategy was the sixth one visualizing words in mind to remember their meaning $(\mathrm{M}=3.42, \mathrm{SD}=1.16)$. On the other hand, learning words considering their lexical classes (item $7, \mathrm{M}=2.67, \mathrm{SD}=1.22$ ) was the least frequently employed strategy by the students.

Table 5. Distribution of memory strategies

\begin{tabular}{|c|c|c|}
\hline Memory strategies & $\overline{\boldsymbol{x}}$ & SD \\
\hline 1. When I forget an English word, I try to remember its synonym. & 2.76 & 1.04 \\
\hline 2. I associate the English words I have learned before with the new ones. & 3.18 & 1.04 \\
\hline 3. In order to remember an English word, I visualise its picture in my mind. & 3.16 & 1.13 \\
\hline $\begin{array}{l}\text { 4. I associate the pronunciation of an English word I have recently learned with } \\
\text { the pronunciation of an English word I know. }\end{array}$ & 2.82 & 1.22 \\
\hline $\begin{array}{l}\text { 5. In order not to forget the English words I have recently learned, I always } \\
\text { repeat them. }\end{array}$ & 3.27 & 1.04 \\
\hline $\begin{array}{l}\text { 6. I try to remember the meaning of an English word by visualizing it in my } \\
\text { mind. }\end{array}$ & 3.42 & 1.17 \\
\hline $\begin{array}{l}\text { 7. While learning English words, I try to learn them according to their lexical } \\
\text { classes (noun, adjective, verb). }\end{array}$ & 2.67 & 1.22 \\
\hline Total & 3.04 & \\
\hline
\end{tabular}

When cognitive VLSs were examined, it was seen that the students reported using item 8 learning words through flashcards least frequently $(\mathrm{M}=1.61, \mathrm{SD}=.970)$. The most Okyar: Vocabulary Learning Strategies of Turkish EFL Learners: A Focus on Gender DOI: https://doi.org/10.33541/jet.v7i1.2289 
favored cognitive strategy by the students was learning words with both synonyms and antonyms (item $12, \mathrm{M}=4.05, \mathrm{SD}=1.161$ ), which was followed by writing words down (item $11, \mathrm{M}=3.81, \mathrm{SD}=1.278$ ) and keeping a vocabulary journal (item $10, \mathrm{M}=3.37, \mathrm{SD}=$ 1.278).

Table 6. Distribution of cognitive strategies

\begin{tabular}{|c|c|c|}
\hline Cognitive strategies & $\overline{\boldsymbol{x}}$ & SD \\
\hline $\begin{array}{l}\text { 8. I try to learn English words by writing them on flashcards and carrying } \\
\text { them in my pocket. }\end{array}$ & 1.61 & .97 \\
\hline $\begin{array}{l}\text { 9. In order to remember English words, I stick the words to the places } \\
\text { where I can see them. }\end{array}$ & 2.02 & 1.19 \\
\hline 10. While learning English words, I keep a vocabulary journal. & 3.37 & 1.24 \\
\hline 11. I study the English words I want to learn by writing them down. & 3.81 & 1.28 \\
\hline 12. I learn English words together with their synonyms and/or antonyms. & 4.05 & 1.16 \\
\hline Total & 2.97 & \\
\hline
\end{tabular}

As for compensation strategies, while the most frequently employed strategy was learning English words through videos (item 15, $\mathrm{M}=3.71, \mathrm{SD}=1.170$ ), the least frequently preferred one was learning words through technological programs (item 14, $\mathrm{M}=2.39, \mathrm{SD}=1.197)$.

Table 7. Distribution of compensation strategies

\begin{tabular}{lcc}
\hline Compensation strategies & $\overline{\boldsymbol{x}}$ & SD \\
\hline 13. I learn the pronunciation of an English word by listening to it several & 2.63 & 1.15 \\
$\begin{array}{l}\text { times with the help of technology. } \\
\text { 14. I prefer to learn English words required for my classes with the help of } \\
\text { technological programs. }\end{array}$ & 2.39 & 1.20 \\
$\begin{array}{l}\text { 15. I prefer to learn English words required for my classes with the help of } \\
\text { videos. }\end{array}$ & 3.71 & 1.17 \\
$\begin{array}{l}\text { 16. I prefer to learn the necessary English words for my classes with the } \\
\text { help of technological games. }\end{array}$ & 3.18 & 1.33 \\
\hline Total & $\mathbf{2 . 9 8}$ & \\
\hline
\end{tabular}

Out of four metacognitive strategies learning both the pronunciation and the meaning of the words (item $18, \mathrm{M}=4.00, \mathrm{SD}=1.054$ ) and trying to find the best method to learn words (item 19, 3.86, $\mathrm{SD}=1.060$ ) were the most frequently preferred strategies by the students.

Table 8. Distribution of metacognitive strategies

\begin{tabular}{lcc}
\hline Metacognitive strategies & $\overline{\boldsymbol{x}}$ & SD \\
\hline 17. While learning English words, I do various English vocabulary tests. & 3.24 & 1.36 \\
18. While learning English words, I try to learn the pronunciation of the & 4.00 & 1.05 \\
words along with the meanings. & & \\
19. I try to find the most suitable method while learning English words. & 3.86 & 1.06 \\
20. While learning English words, I stick to a plan. & 3.09 & 1.25 \\
\hline Total & $\mathbf{3 . 5 5}$ & \\
\hline
\end{tabular}


When affective strategies are considered, "I feel much more comfortable in class when I improve my English vocabulary knowledge" (item 24, $\mathrm{M}=4.38, \mathrm{SD}=.918$ ) and "It attracts my attention when the words I know are used in a video or in a movie" (item $26, \mathrm{M}=4.38, \mathrm{SD}=1.012$ ) were the most reported ones with the same mean score. However, item 22, "When I learn English words, I reward myself" was the least frequently preferred affective strategy $(\mathrm{M}=2.28, \mathrm{SD}=1.370)$.

Table 9. Distribution of affective strategies

\begin{tabular}{lrr}
\hline Affective strategies & $\overline{\boldsymbol{x}}$ & \multicolumn{1}{c}{ SD } \\
\hline $\begin{array}{l}\text { 21. While learning English words, listening to music in the background } \\
\text { helps me relax. }\end{array}$ & 2.67 & 1.50 \\
$\begin{array}{l}\text { 22. When I learn English words, I reward myself. } \\
\text { 23. I feel happy when I learn English words. }\end{array}$ & 2.28 & 1.37 \\
$\begin{array}{l}\text { 24. I feel much more comfortable in class when I improve my English } \\
\quad \text { vocabulary knowledge. }\end{array}$ & 4.15 & 1.08 \\
$\begin{array}{l}\text { 25. Our teacher encourages us to learn English words outside the } \\
\quad \text { classroom as well. }\end{array}$ & 3.69 & 1.25 \\
$\begin{array}{l}\text { 26. It attracts my attention when the words I know are used in a video or } \\
\text { in a movie. }\end{array}$ & 4.38 & 1.01 \\
\hline Total & $\mathbf{3 . 5 9}$ & \\
\hline
\end{tabular}

Out of six items from social strategies, the most preferred one was: "I ask my friends to correct me when I mispronounce the English words that I have recently learned" (item $28, \mathrm{M}=3.11, \mathrm{SD}=1.414)$. The least frequently employed strategy was working in groups to learn words (item 29, $\mathrm{M}=2.22, \mathrm{SD}=1.311$ ).

Table 10. Distribution of social strategies

\begin{tabular}{lcc}
\hline Social strategies & $\overline{\boldsymbol{x}}$ & SD \\
\hline $\begin{array}{l}\text { 27. I ask my friends whether I correctly pronounce the English words I have } \\
\text { recently learned. }\end{array}$ & 3.07 & 1.39 \\
$\begin{array}{l}\text { 28. I ask my friends to correct me when I mispronounce the English words } \\
\text { that I have recently learned. }\end{array}$ & 3.11 & 1.41 \\
$\begin{array}{l}\text { 29. While trying to learn English words, I prefer working in a group. } \\
\text { 30. While learning English words, I need the assistance of my teacher. }\end{array}$ & 2.22 & 1.31 \\
$\begin{array}{l}\text { 31. While learning English words, I prefer working with the class to } \\
\quad \text { individual work. }\end{array}$ & 2.76 & 1.30 \\
32. I learn English words better by competing with my friends. & 2.34 & 1.54 \\
\hline Total & $\mathbf{2 . 6 9}$ & \\
\hline
\end{tabular}

\section{Relationship between VLSs and gender}

The second research question investigated whether male and female students differed in VLS use. As shown in the table below, females had a higher mean score on VLS use than males, as follows: males $(\mathrm{M}=2.96, \mathrm{SD}=.53)$ and females $(\mathrm{M}=3.30, \mathrm{SD}=.43)$. $\mathrm{T}$ test results revealed a statistically significant difference between them regarding VLS use frequency, $\mathrm{t}(207)=5.054, \mathrm{p}=.000$. 
Table 11. T-test results for VLS use by gender

\begin{tabular}{llcccc}
\hline Groups & $\overline{\boldsymbol{x}}$ & SD & t & df & p \\
\hline Male $(\mathrm{n}=108)$ & 2.96 & .53 & 5.054 & 207 & 000 \\
Female $(\mathrm{n}=101)$ & 3.30 & .43 & & & \\
\hline
\end{tabular}

Further analysis of the subcategories of VLSs indicated that there was a statistically significant difference between male and female students with the following strategies: memory strategies $(\mathrm{t}=3.627, \mathrm{p}<.05)$, cognitive strategies $(\mathrm{t}=6.222, \mathrm{p}<.05)$, compensation strategies $(\mathrm{t}=2.383, \mathrm{p}<.05)$, metacognitive strategies $(\mathrm{t}=4.206, \mathrm{p}<.05)$, and affective strategies $(t=2.629, p<.05)$. That is to say, female students were superior to males in the frequency of use of these five strategies. On the other hand, there was no statistically significant difference between males and females in terms of social strategies $(t=1.909$, $\mathrm{p}>.05)$.

Table 12. T-test results for the use of VLS sub-categories by gender

\begin{tabular}{|c|c|c|c|c|c|c|c|}
\hline VLS Sub-categories & Gender & $\mathbf{N}$ & $\bar{x}$ & SD & $\mathbf{t}$ & df & p \\
\hline \multirow[t]{2}{*}{ Memory strategies } & Female & 101 & 3.21 & .60 & 3.627 & 207 & .000 \\
\hline & Male & 108 & 2.88 & .69 & & & \\
\hline \multirow[t]{2}{*}{ Cognitive strategies } & Female & 101 & 3.29 & .68 & 6.222 & 207 & .000 \\
\hline & Male & 108 & 2.68 & 73 & & & \\
\hline \multirow[t]{2}{*}{ Compensation strategies } & Female & 101 & 3.12 & .80 & 2.383 & 207 & .018 \\
\hline & Male & 108 & 2.85 & .84 & & & \\
\hline \multirow[t]{2}{*}{ Metacognitive strategies } & Female & 101 & 3.77 & .68 & 4.206 & 207 & .000 \\
\hline & Male & 108 & 3.34 & .79 & & & \\
\hline \multirow[t]{2}{*}{ Affective strategies } & Female & 101 & 3.72 & .56 & 2.629 & 197.155 & .009 \\
\hline & Male & 108 & 3.48 & .75 & & & \\
\hline \multirow[t]{2}{*}{ Social strategies } & Female & 101 & 2.81 & .84 & 1.909 & 207 & .058 \\
\hline & Male & 108 & 2.58 & .88 & & & \\
\hline
\end{tabular}

\section{DISCUSSION}

This study found that the students employed VLSs moderately. As for the sub-categories of the strategies, the results demonstrated that affective strategies were the most frequently employed ones out of the six VLSs. This finding suggests that emotions play a very important role in the learning process. Affect, according to Gass, Behney and Plonsky (2013) "refers to feelings or emotions that individuals have about something. In the case of language learning, it can refer to feelings or emotional reactions about the language..." (p. 459). When we consider the importance of each individual's feelings towards the language they learn, we can say that creating positive emotions in learners is very important. As seen clearly, most of the students in this study indicated that they feel happier and more comfortable when they see that they have made progress in learning new words. This shows how important language learners' emotions are during vocabulary learning process.

As for metacognitive strategies, most students reported that they tried to find the best ways to learn vocabulary. This shows that they try to take responsibility for their own vocabulary learning, which may be linked as well to learner autonomy. When cognitive strategies are considered, only a few students preferred learning words through flashcards; however, most of them favored writing words and learning them with both synonyms and antonyms. Based on this, it can be said that learners choose more practical 
ways to learn vocabulary. As for memory strategies, visualization of the word in mind was favored by most of the students. This may be because visuals help learners remember things better.

When social strategies are examined, students' self-reports revealed that they were the least frequently employed strategies. With this finding, this study supports the findings of some previous studies (e.g. Mirioglu, 2020; Schmitt, 1997; Tilfarlioglu \& Bozgeyik, 2012) which also found that social strategies were the least frequently preferred strategies by the students. In the present study, very few students preferred to work in groups to learn vocabulary. Similarly, in Schmitt's (1997) study, it was emphasized that Japanese students preferred individual learning while studying vocabulary. Different factors like culture can have effects on students' preferences to work individually or in groups. Another reason could be that students are not encouraged enough to interactively work with their peers. Now that we believe interaction is crucial in language learning (Gass et al., 2013), learners should be encouraged to study vocabulary with their peers in pairs or groups.

The results of the present study are also in line with earlier studies like those of Jimenez Catalan (2003) and $\mathrm{Gu}$ (2002) which reported significant differences between females and males, with females being superior to males in terms of the total number of VLSs used. According to this recent study's findings, female students reported using five out of six strategy sub-categories more than their male counterparts. This may be linked to the motivation factor. As stated by Jimenez Catalan (2003) and some previous studies (see Bacon \& Finnemann, 1992; Shaaban \& Ghaith, 2000) females are more motivated to learn languages, and for this reason, they are more motivated to learn vocabulary and use strategies that help them improve their vocabulary. In other words, female students' high motivation to learn languages may indirectly and positively affect their use of VLSs to learn new words. However, there are also studies that contradict the findings of the present one. For instance, as mentioned earlier, Lee (2007) and Wei (2007) did not find any significant difference between the two genders' VLS use. These different results may be due to learners' L2 motivation level, cultural factors, learning context, and so on. This also reminds us of what some researchers said before. According to $\mathrm{Gu}$ (2002), literature related to second language acquisition generally shows females' language learning superiority over males; however, current research studies show that these results may vary when different learning contexts and learning tasks are considered. The contradictory results make it difficult to get a clear picture of gender difference in VLS use, and so make it necessary to do more research on this topic.

\section{CONCLUSION AND SUGGESTION}

This study aimed to help fill the gap in the literature by investigating EFL learners' VLS use and comparing female and male students' VLS uses. As the results show, the students reported using VLSs moderately, and while affective strategies were the most frequently used strategies, social strategies were the least frequently employed ones among the others. Besides, gender difference in VLS use is confirmed in this study. Considering these results and the important role of word knowledge in language, it is recommended that language teachers should raise students' awareness in terms of the types of VLSs and encourage and train both male and female students to use VLSs as frequently and effectively as possible. In addition to this, Schmitt (2000) suggests that the whole learning context with its various variables such as "proficiency level, L1 and culture of students, their motivation and purposes for learning the L2, the task and text being used, and the Okyar: Vocabulary Learning Strategies of Turkish EFL Learners: A Focus on Gender DOI: https://doi.org/10.33541/jet.v7i1.2289 
nature of the L2 itself" should be taken into account while deciding what VLSs to teach and use. It is of utmost importance for teachers to model and use strategies during L2 teaching classes so this can prepare learners to study vocabulary independently in later times (Schmitt, 2000; Zimmerman, 2014). Therefore, at the beginning of the school year, teachers can try to find out whether their students are familiar with VLSs or not, and integrate the active teaching of VLSs into their teaching program. In light of the previously mentioned findings, this study offers some suggestions for further research. For instance, future studies may focus on the reasons behind female students' tendency to use VLSs more than their male counterparts. Furthermore, male and female students' VLS use can be investigated considering different factors like their L2 learning motivation, autonomy, and L2 proficiency level.

\section{REFERENCES}

Bacon, S. \& Finnemann, M. (1992). Sex differences in self-reported beliefs about foreign language learning and authentic oral and written input. Language Learning, 42, 471-495.

Brown, H. D. (2007). Teaching by principles: An interactive approach to language pedagogy (3rd ed.). White Plains, NY: Pearson.

Gass, S. M., Behney, J., \& Plonsky, L. (2013). Second language acquisition: An introductory course (4th ed.). New York: Routledge.

$\mathrm{Gu}$, Y. (2002). Gender, academic major, and vocabulary learning strategies of Chinese EFL learners. RELC Journal, 33(1), 35-54.

Jimenez Catalan, R. M. (2003). Sex differences in L2 vocabulary learning strategies. International Journal of Applied Linguistics, 13(1), 54-77.

Kocaman, O., \& Kizilkaya Cumaoglu, G. (2014). Developing a scale for vocabulary learning strategies in foreign languages. Education and Science, 39(176), 293-303.

Lee, S. (2007). Vocabulary learning strategies of Korean university students: Strategy use, vocabulary size, and gender. English Teaching, 62(1), 149-169.

Mirioglu, M. (2020). Investigating the importance level and utilization of vocabulary learning strategies among Turkish EFL learners. Asian Journal of University Education, 16(1), 32-45.

Nation, I.S.P. (2000). Learning vocabulary in another language. Cambridge: Cambridge University Press.

Oxford, R., Nyikos, M., \& Ehrman, M. (1988). Vive la difference? Reflections on sex differences in use of language learning strategies. Foreign Language Annals, 21(4): 321-329.

Oxford, R. L. (1990). Language Learning Strategies: What Every Teacher Should Know. Boston: Newbury House.

Schmitt, N. (1997). Vocabulary learning strategies. In N. Schmitt \& M. McCarthy (Eds.), Vocabulary: Description, acquisition, and pedagogy (pp.199-227). Cambridge: Cambridge University Press.

Schmitt, N. (2000). Vocabulary in language teaching. Cambridge: Cambridge University Press. 
Schmitt, N. (2010). Researching vocabulary: A vocabulary research manual. Basingstoke: Palgrave Macmillan.

Shaaban, K. A. \& Ghaith, G. M. (2000). Student motivation to learn English as a foreign language. Foreign Language Annals, 33, 632-644.

Tilfarlioglu, F. \& Bozgeyik, Y. (2012). The Relationship between vocabulary learning strategies and vocabulary proficiency of English language learners. International Journal of Applied Linguistics and English Literature, 1(2), 91-101.

Wei, M. (2007). An examination of vocabulary learning of college-level learners of English in China. The Asian EFL Journal Quarterly, 9(2) 93-114.

Zimmerman, C. B. (2014). Teaching and learning vocabulary for second language learners. In M. Celce-Murcia, D. Brinton, and M.A. Snow (eds.) Teaching English as a second or foreign language (pp. 288-302). Boston: National Geographic Learning/Cengage. 